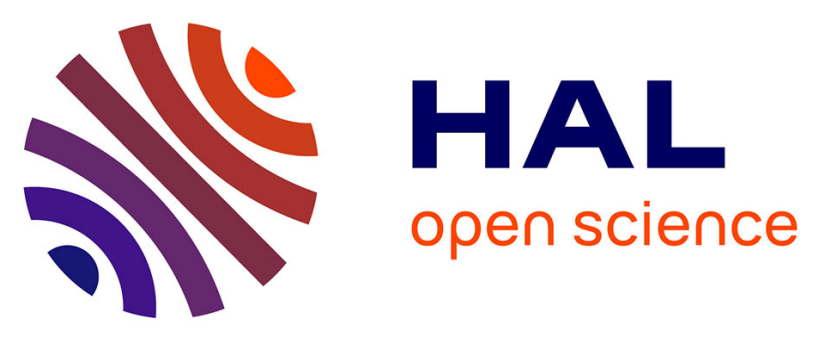

\title{
Synthesis and fluorine-mediated interactions in methanol-encapsulated solid state self-assembly of an isatin-thiazoline hybrid
}

Humayun Pervez, Maqbool Ahmad, Taibi B. Hadda, Loic Toupet, Muhammad Moazzam Naseer

\section{To cite this version:}

Humayun Pervez, Maqbool Ahmad, Taibi B. Hadda, Loic Toupet, Muhammad Moazzam Naseer. Synthesis and fluorine-mediated interactions in methanol-encapsulated solid state selfassembly of an isatin-thiazoline hybrid. Journal of Molecular Structure, 2015, 1098, pp.124-129. 10.1016/j.molstruc.2015.06.013 . hal-01168327

HAL Id: hal-01168327

https://hal-univ-rennes1.archives-ouvertes.fr/hal-01168327

Submitted on 18 Nov 2015

HAL is a multi-disciplinary open access archive for the deposit and dissemination of scientific research documents, whether they are published or not. The documents may come from teaching and research institutions in France or abroad, or from public or private research centers.
L'archive ouverte pluridisciplinaire HAL, est destinée au dépôt et à la diffusion de documents scientifiques de niveau recherche, publiés ou non, émanant des établissements d'enseignement et de recherche français ou étrangers, des laboratoires publics ou privés. 


\title{
Synthesis and fluorine-mediated interactions in methanol-encapsulated solid state self-assembly of an isatin-thiazoline hybrid
}

\author{
Humayun Pervez ${ }^{\mathrm{a}}$, Maqbool Ahmad ${ }^{\mathrm{a}}$, Taibi B. Hadda ${ }^{\mathrm{b}}$, Loic Toupet ${ }^{\mathrm{c}}$, Muhammad Moazzam \\ Naseer $^{\mathrm{d} *}$ \\ ${ }^{a}$ Institute of Chemical Sciences, Organic Chemistry Division, Bahauddin Zakariya University, Multan 60800, \\ Pakistan \\ ${ }^{b}$ Laboratoire de Chimie des Matériaux (LCM), Faculté des Sciences d'Oujda (FSO), Université Mohammed 1Er, \\ 60000-Oujda, Morocco \\ ${ }^{c}$ Institut de Physique de Rennes, UMR 625, Université de Rennes 1, Campus de Beaulieu Bat. 11 A, 263 av. Général \\ Leclerc, 35042 Rennes Cedex, France \\ ${ }^{\mathrm{d}}$ Department of Chemistry, Quaid-i-Azam University, Islamabad 45320, Pakistan
}

\begin{abstract}
An exciting isatin-thiazoline hybrid molecule 2 having $-\mathrm{C}=\mathrm{N}-\mathrm{N}=\mathrm{C}$ - linkage has been synthesized in $88 \%$ yield by the reaction of 5-fluoroisatin with $N$-(4fluorophenyl)hydrazinecarbothioamide followed by condensation of the resultant isatinthiosemicarbazone intermediate with $p$-chlorophenacyl bromide. The solid state self-assembly of this hybrid molecule was studied by X-ray crystallographic technique. A layered assembly composed of 1D-chains with methanol molecules encapsulated between every two chains is obtained, making a bi-chain sandwich like structure. The supramolecular forces involved in the stabilization of this structure are importantly fluorine-mediated interactions $(\mathrm{C}-\mathrm{H} \cdots \mathrm{F}, \mathrm{F} \cdots \mathrm{S}$ and $\mathrm{F} \cdots \pi)$ along with others i.e. $\mathrm{N}-\mathrm{H} \cdots \mathrm{O}, \mathrm{O}-\mathrm{H} \cdots \mathrm{O}, \mathrm{C}-\mathrm{H} \cdots \mathrm{O}, \mathrm{Cl} \cdots \pi, \mathrm{C}-\mathrm{H} \cdots \pi$ and $\pi \cdots \pi$ interactions. To the best of our knowledge, this is the first example of solid state fluorine-mediated C-H...F, F $\cdots$ S and F $\cdots \pi$ interactions found in a family of isatin-based compounds.
\end{abstract}

Keywords: isatin-thiazoline hybrid; synthesis; self-assembly; fluorine-mediated interactions; layered structure

\footnotetext{
"Corresponding authors. tel.: +92 51 90642129; fax:+92 5190642241 (M.M.N.).

E-mail addresses: moazzam@qau.edu.pk (M.M. Naseer), pdhpervez@,hotmail.com (H. Pervez).
} 


\section{Introduction}

Weaker hydrogen bonds of the $\mathrm{C}-\mathrm{H} \cdots \mathrm{X}-\mathrm{C}$ type play an important role in the stabilization of crystal structures. Hence, the $\mathrm{C}-\mathrm{H} \cdots \mathrm{O}, \mathrm{C}-\mathrm{H} \cdots \mathrm{N}$, and $\mathrm{C}-\mathrm{H} \cdots \mathrm{Cl}$ hydrogen bonds have increasingly been used in crystal engineering [1-11]. However, the interactions involving "organic fluorine" i.e. C-H $\cdots \mathrm{F}$ interactions have always been a controversial subject in contemporary research and their nature still remains obscure [12-17]. According to Pauling's definition of the hydrogen bond, $\mathrm{F}$ atom should be a stronger hydrogen bond acceptor than $\mathrm{O}$ and $\mathrm{N}$ atoms due to its high electronegativity [18]. But practically, it does not form hydrogen bonds commensurate with electronegativity considerations and has been considered as a very poor acceptor in supramolecular chemistry [14]. Recently, this interaction was evaluated by ab initio calculations and found to be much more important in defining the crystal packing than portrayed earlier [19].

In addition to $\mathrm{C}-\mathrm{H} \cdots \mathrm{F}$ interactions, $\mathrm{F} \cdots \mathrm{X}(\mathrm{X}=\mathrm{S}, \pi)$ interactions are the other relatively weak interactions that have recently been recognized in organic fluorinated molecules [20-24]. It is now well-established that drug molecules containing one or more fluorine atoms show superior biological properties as compared to their non-fluorinated analogues perhaps due to better interactions with the receptor sites in our body [25]. Because of its small size, fluorine is also an ideal substituent where change in the electronic properties of the molecules is needed without affecting the steric environment. Furthermore, its lipophilic character also plays an important role in increasing the bioavailability of fluorinated drug molecules [26]. Therefore, more efforts are necessary for appropriate understanding of the intermolecular interactions offered by the fluorine atom. 
Isatin (indole-1H-2,3-dione) is undoubtedly a privileged scaffold for chemical modification due to its presence in a number of naturally occurring substances $[27,28]$. Although, a number of its derivatives have been prepared through electrophilic aromatic substitution at positions C-5 and $\mathrm{C}-7$ of the phenyl ring and by $N$-substitution, but the most important and fascinating site for the purpose is C-3 carbonyl group due to its high reactivity with various nucleophiles. It generally undergoes nucleophilic addition or spiroannulation at this position, providing a broad range of 2-oxindole derivatives of immense biological importance [27,28]. Furthermore, isatin is structurally an ideal candidate to serve as a highly variable tecton for the construction of supramolecular assemblies due to its remarkable hydrogen bond donor/acceptor abilities and a relatively large molecular dipole moment [29-31]. Keeping this in view, we very recently reported the synthesis and solid state self-assembly of 5-fluoroisatin-based hybrid molecule $\mathbf{1}$, where no intermolecular interactions were observed for fluoro substituent in the presence of $\mathrm{N}$ $\mathrm{H} \cdots \mathrm{O}, \mathrm{C}-\mathrm{H} \cdots \mathrm{O}, \mathrm{C}-\mathrm{H} \cdots \mathrm{N}, \mathrm{C}-\mathrm{H} \cdots \pi, \pi \cdots \pi, \mathrm{C}-\mathrm{H} \cdots \mathrm{Cl}$ interactions [32]. This observation and our continuous interest in supramolecular self-assemblies [33-39] increased our curiosity and prompted us to introduce 4-fluoro group as a substitute to 3-methoxy on the central $\mathrm{N}$-aryl ring of the rigid core of isatin-thiazoline hybrid $\mathbf{1}$ to explore the existence of fluorine-mediated interactions in isatin-based compounds. Pleasingly, the approach remained successful and herein, we report the synthesis and methanol-encapsulated layered assembly of isatin-thiazoline hybrid $\mathbf{2}$ with unprecedented $\mathrm{C}-\mathrm{H} \cdots \mathrm{F}, \mathrm{F} \cdots \mathrm{S}$ and $\mathrm{F} \cdots \pi$ interactions in a vast library of isatin-based compounds. In addition, this also represents one of the rare examples of fluorine-mediated interactions found in the presence of other strong non-covalent interactions reported so far [4042]. 
<smiles>COc1cccc(-n2c(-c3ccc(Cl)cc3)cs/c2=N\N=C2/C(=O)Nc3ccc(F)cc32)c1</smiles>

1<smiles>O=C1Nc2ccc(F)cc2/C1=N\N=c1/scc(-c2ccc(Cl)cc2)n1-c1ccc(F)cc1</smiles>

2

Figure 1. Molecular structures of isatin-thiazoline hybrids $\mathbf{1}$ and $\mathbf{2}$

\section{Experimental}

\subsection{Materials and Methods}

All regents and solvents were used as obtained from the supplier or recrystallized or redistilled as necessary. Thin layer chromatography (TLC) using glass plates coated with Silica gel $60 \mathrm{GF}_{254}$ (E.Marck) was performed to check the progress of the reaction and the purity of the product. The spots were visualized under ultraviolet light at 254 and $366 \mathrm{~nm}$ and / or spraying with iodine vapours. Melting point was taken on a Fisher-Johns melting point apparatus and is uncorrected. Elemental analysis was performed on a Leco CHNS-9320 elemental analyzer. Infrared spectrum (KBr disk) was run on Shimadzu 8400. ${ }^{1} \mathrm{H}-\mathrm{NMR}$ spectrum was recorded in $\mathrm{C}_{2} \mathrm{D}_{6} \mathrm{SO}$ on Bruker (Rhenistentten-Forchheim, Germany) AM 300 spectrometer operating at $300 \mathrm{MHz}$, using TMS as an internal standard. ${ }^{1} \mathrm{H}$ chemical shifts are reported in (ppm) and coupling constants in $\mathrm{Hz}$. Mass spectrum was recorded on agilent 6310 ion trap LC/MS mass spectrometer.

Procedure for the preparation of (3Z)-5-fluoro-1H-indole-2,3-dione 3-\{[(2Z)-4-(4chlorophenyl)-3-(4-fluorophenyl)-1,3-thiazol-2(3H)-ylidene]hydrazone\} (2) 
To a solution of 5-fluoroisatin $(0.01 \mathrm{~mol})$ in $50 \%$ aqueous EtOH $(20 \mathrm{~mL})$ containing a catalytic amount of glacial $\mathrm{AcOH}$ was added an ethanolic solution $(20 \mathrm{~mL})$ of $\mathrm{N}$-(4fluorophenyl)hydrazinecarbothioamide $(0.01 \mathrm{~mol})$ with constant stirring. The reaction mixture was then refluxed for $2 \mathrm{~h}$. The solid obtained during refluxing was collected by suction filtration. Thorough washing with hot aqueous EtOH (50\%) afforded the desired thiosemicabazone, which was used as such without further purification [43]. The synthesized thiosemicabazone $(0.005$ mol) was subsequently mixed with $p$-chlorophenacyl bromide $(0.005 \mathrm{~mol})$ in absolute EtOH (25 $\mathrm{mL}$ ) and heated under reflux for $15 \mathrm{~h}$. The refluxate was concentrated on rotary evaporator and the precipitate thus formed was filtered. Thorough washing with $n$-hexane followed by crystallization from water/ethanol furnished the target compound $\mathbf{2}$ in pure form. The synthesized compound $\mathbf{2}$ is characterized as follows:

Yield $88 \%$ as orange yellow crystals; m.p. $298-300{ }^{\circ} \mathrm{C}$; IR $\left(\mathrm{KBr}, \mathrm{cm}^{-1}\right): 3177(\mathrm{NH}$ stretching), $1705(\mathrm{C}=\mathrm{O}), 1624(\mathrm{C}=\mathrm{N}) ;{ }^{1} \mathrm{H}-\mathrm{NMR}\left(\mathrm{DMSO}-d_{6}, \delta, \mathrm{ppm}\right): 6.75(\mathrm{dd}, J=8.7,4.5 \mathrm{~Hz}, 1 \mathrm{H}$, indole $\left.\mathrm{C}_{7}-\mathrm{H}\right), 7.03\left(\mathrm{td}, J=9.3,2.7 \mathrm{~Hz}, 1 \mathrm{H}\right.$, indole $\left.\mathrm{C}_{6}-\mathrm{H}\right), 7.09\left(\mathrm{dd}, J=9.0,2.7 \mathrm{~Hz}, 1 \mathrm{H}\right.$, indole $\left.\mathrm{C}_{4}-\mathrm{H}\right)$, $7.11(\mathrm{~s}, 1 \mathrm{H}$, thiazoline $=\mathrm{CH}), 7.29\left(\mathrm{~d}, J=8.7 \mathrm{~Hz}, 2 \mathrm{H}\right.$, phenyl $\left.\mathrm{C}_{2}-\mathrm{H}, \mathrm{C}_{6}-\mathrm{H}\right), 7.37(\mathrm{t}, J=8.7 \mathrm{~Hz}$, $2 \mathrm{H}, N$ - phenyl $\left.\mathrm{C}_{2}-\mathrm{H}, \mathrm{C}_{6}-\mathrm{H}\right), 7.41\left(\mathrm{~d}, J=8.7 \mathrm{~Hz}, 2 \mathrm{H}\right.$, phenyl $\left.\mathrm{C}_{3}-\mathrm{H}, \mathrm{C}_{5}-\mathrm{H}\right), 7.55(\mathrm{dd}, J=8.7,4.5$ $\mathrm{Hz}, 2 \mathrm{H}, \mathrm{N}$-phenyl $\left.\mathrm{C}_{3}-\mathrm{H}, \mathrm{C}_{5}-\mathrm{H}\right), 10.50(\mathrm{~s}, 1 \mathrm{H}$, indole $\mathrm{NH})$; EIMS $(70 \mathrm{eV}) \mathrm{m} / \mathrm{z}(\%): 468\left(\mathrm{M}^{+}+2\right.$, 75), $467\left(\mathrm{M}^{+}+1,55\right), 466\left(\mathrm{M}^{+}, 100\right), 440(8), 439$ (9), 438 (18), 437 (11), 305 (6), 304 (8), 303 (12), 292 (35), 291 (19), 290 (82), 288 (22), 234 (7), 232 (16), 170 (8), 168 (19), 153 (26), 149 (13), 136 (9), 134 (7), 133 (6), 121 (12), 108 (6), 95 (14), 75 (7); Anal calcd. for $\mathrm{C}_{23} \mathrm{H}_{13} \mathrm{ClF}_{2} \mathrm{~N}_{4} \mathrm{OS}$ : C 59.16, H 2.79, N 12.00; found: C 59.16, H 2.77, N 11.99.

\subsection{Crystallographic data collection and structure refinements}


Suitable X-ray quality crystals of compound $\mathbf{2}$ were obtained by slow evaporation of its solution in dichloromethane-methanol solvent mixture at ambient temperature. Single crystal X-ray structural studies of $\mathbf{2}$ were performed on a CCD Oxford Diffraction XcaliburSaphir 3 diffractometer, employing graphite-monochromated Mo-K $\alpha$ radiation generated from a finefocus sealed tube $(\lambda=0.71073 \AA)$ at $150(2) \mathrm{K}$. Data collection strategy was evaluated by using the CrysAlisPro CCD software. Collections of data were observed by the standard $\omega$ scan techniques and were scaled and reduced using CrysAlisPro RED software. The structure was solved by direct methods using SIR-97 [44] and refined by least-squares methods on F2 using SHELXL-97 [45]. The positions of all the atoms were obtained by direct methods. Anisotropic thermal parameters were assigned to all non-hydrogen atoms and the remaining hydrogen atoms were placed in geometrically constrained positions and refined as riding atoms with a common fixed isotropic thermal parameter. The drawing of the complex was realized with PLATON [46]. A summary of the selected crystallographic information is given in Table 1.

Table 1. Crystal data and structure refinement for $\mathbf{2}$

\begin{tabular}{ll}
\hline Crystal data & $\mathbf{2}$ \\
\hline CCDC & 981215 \\
Chemical formula & $\mathrm{C}_{24} \mathrm{H}_{17} \mathrm{ClF}_{2} \mathrm{~N}_{4} \mathrm{O}_{2} \mathrm{~S}$ \\
$M_{\mathrm{r}}$ & 498.93 \\
Crystal system, space group & Monoclinic, $P 2_{1} / c$ \\
Temperature (K) & 150 \\
$a, b, c(\AA)$ & $9.6361(4), 10.6068(3), 22.6225(7)$ \\
$\beta\left({ }^{\circ}\right)$ & $97.549(3)$ \\
$V\left(\AA^{3}\right)$ & $2292.16(14)$ \\
$Z$ & 4 \\
Radiation type & $M 0 K \alpha$ \\
$\mu\left(\mathrm{mm}^{-1}\right)$ & 0.30
\end{tabular}


Crystal size $(\mathrm{mm})$

\section{Data collection}

Diffractometer

Absorption correction

No. of measured, independent and observed $[/>2 \sigma(I)]$ reflections

$R_{\text {int }}$

$(\sin \theta / \lambda)_{\max }\left(\AA^{-1}\right)$

Refinement

$R\left[F^{2}>2 \sigma\left(F^{2}\right)\right], w R\left(F^{2}\right), S$

No. of reflections

No. of parameters

$\mathrm{H}$-atom treatment

$\left.\Delta\rangle_{\max }, \Delta\right\rangle_{\min }\left(\mathrm{e} \AA^{-3}\right)$
$0.29 \times 0.19 \times 0.13$

CCD Saphire 3 Xcalibur

diffractometer

$19330,5008,4183$

0.032

0.639

$0.033,0.086,1.02$

5008

308

$\mathrm{H}$-atom parameters constrained

$0.30,-0.27$

\section{Results and discussion}

As depicted in Scheme 1, isatin-thiazoline hybrid molecule 2 was synthesized by reacting 5fluoroisatin with one equivalent of $N$-(4-fluorophenyl)hydrazinecarbothioamide in ethanol solvent containing a catalytic amount of glacial acetic acid in the first step and then treating the resultant product dissolved in absolute ethanol with 4-chlorophenacyl bromide at reflux temperature in the second step. 


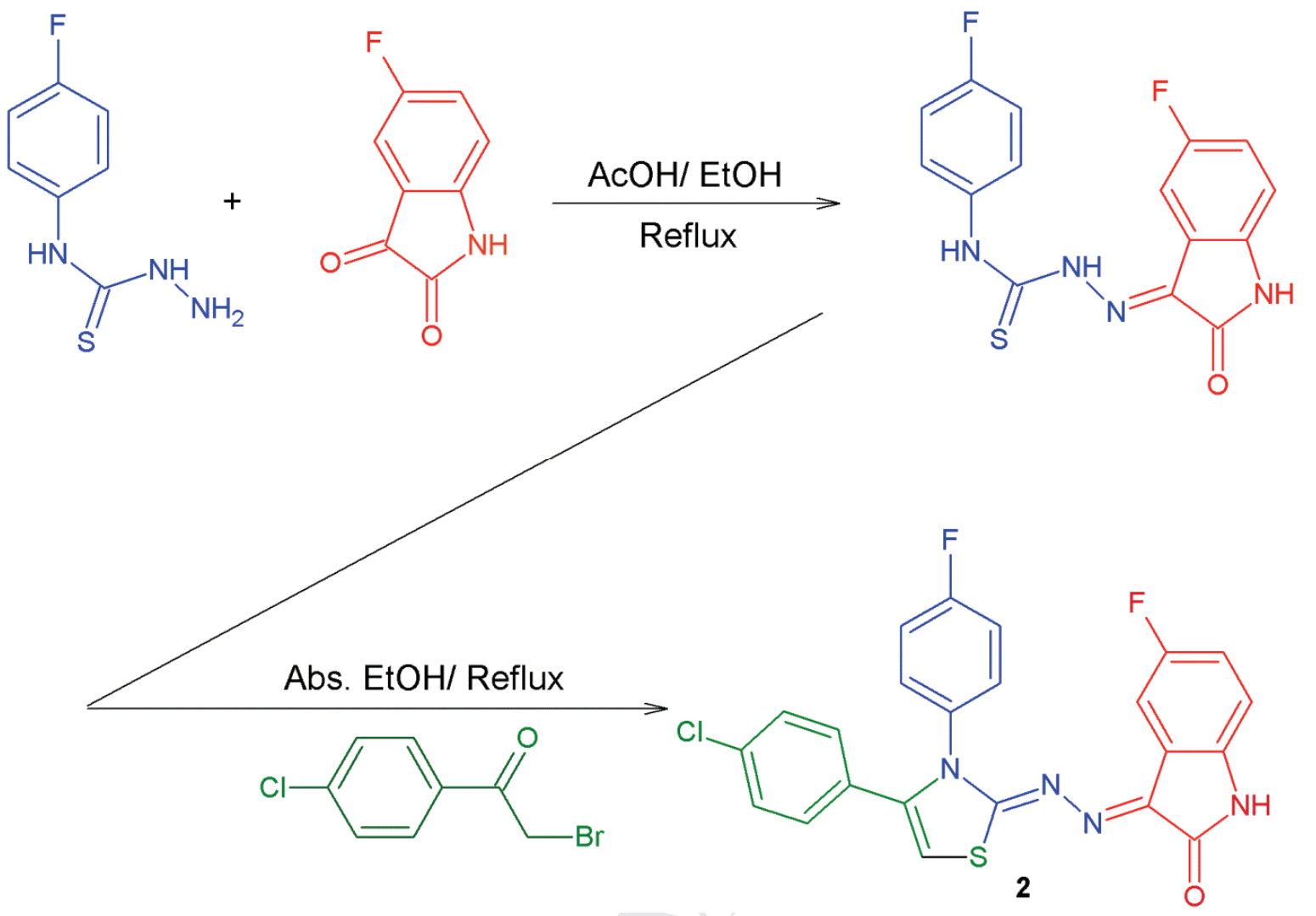

Scheme 1. Synthesis of isatin-thiazoline hybrid molecule 2

Single crystals of 2, suitable for X-ray analysis (Figure 2, Table 1) were cultivated in a dichloromethane/methanol solvent mixture by slow evaporation method and found to have a monoclinic crystal lattice with the $P 21 / c$ space group. It is important to mention here that these are the same conditions for crystal growth as used previously for compound 1 [32]. In this compound, isatin and the central thiazoline rings that are connected with each other through $\mathrm{C}=\mathrm{N}-\mathrm{N}=\mathrm{C}$ - linkage lie nearly in the same plane. However, the two aryl rings substituted on thiazoline moiety are tilted as compared to the plane of isatin-thiazoline rings. The fluorosubstituted aryl ring present at N4-of the thiazoline moiety is positioned in such a way that H5 of the isatin is located on almost top and the centre of its aromatic ring plane with a distance of $2.977 \AA$. The dihedral angle between the plane of fluoro-substituted aryl and thiazoline rings is 
$69.67^{\circ}$ (C9-N4-C18-C19). The chloro-substituted aryl ring at C-10 of the thiazoline ring is less tilted as compared to the N4-aryl one with a dihedral angle of $42.06^{\circ}$ (N4-C10-C12-C17) from the isatin-thiazoline plane. In the thiazoline ring, the $\mathrm{S}(1)-\mathrm{C}(9)$ and $\mathrm{S}(1)-\mathrm{C}(11)$ bond lengths are 1.733(14) $\AA$ and $1.735(15) \AA$, respectively, with the $\mathrm{C}(9)-\mathrm{S}(1)-\mathrm{C}(11)$ bond angle being $90.10(7)^{\circ}$. Other selected bond lengths and bond angles are presented in the caption to figure 2.

The most significant and interesting feature of this compound is its molecular packing in the solid state, stabilized by fluorine-mediated interactions $(\mathrm{C}-\mathrm{H} \cdots \mathrm{F}, \mathrm{F} \cdots \mathrm{S}$ and $\mathrm{F} \cdots \pi)$ (Figure 3$)$ in addition to other non-covalent interactions $(\mathrm{N}-\mathrm{H} \cdots \mathrm{O}, \mathrm{O}-\mathrm{H} \cdots \mathrm{O}, \mathrm{C}-\mathrm{H} \cdots \mathrm{O}, \mathrm{Cl} \cdots \pi, \mathrm{C}-\mathrm{H} \cdots \pi, \pi \cdots \pi)$ (Table 2). The crystal structure revealed methanol-encapsulated layered assembly, composed of 1D-supramolecular chains (Figure 4). As shown in figures $4 \mathrm{a} \& 4 \mathrm{~b}$, methanol molecules are sandwiched between every two chains of a layer. Each 1D-chain of this assembly is formed by the lateral arrangement of molecules by means of $F \cdots S[F(1) \cdots S(1) 3.014 \AA]$ and $F \cdots \pi[F(1)$ ‥C(11) $3.123 \AA$ ] interactions. The molecules in every chain of a layer with respect to another are inverted. Two neighbouring chains, which are encapsulating the methanol molecules by means of mainly $\mathrm{N}-\mathrm{H} \cdots \mathrm{O}[\mathrm{N}(1)-\mathrm{H}(1) \cdots \mathrm{O}(2) 1.981 \AA]$, O-H $\cdots \mathrm{O}[\mathrm{O}(2)-\mathrm{H}(2 \mathrm{~A}) \cdots \mathrm{O}(1) 1.871 \AA]$ and $\mathrm{C}-\mathrm{H} \cdots \mathrm{O}[\mathrm{C}(3)-\mathrm{H}(3) \cdots \mathrm{O}(2) 2.521 \AA]$ interactions, are connected with each other through $\mathrm{C}$ $\mathrm{H} \cdots \mathrm{O}[\mathrm{C}(2)-\mathrm{H}(2) \cdots \mathrm{O}(1) 2.448 \AA]$ interactions. The two consecutive chains, which are sandwiching the methanol molecules (a bi-chain sandwich) are connected to the next bi-chain sandwich with the help of $\mathrm{Cl} \cdots \pi[\mathrm{Cl}(1) \cdots \mathrm{C}(20) 3.406 \AA$, $\mathrm{Cl}(1) \cdots \mathrm{C}(21) 3.261 \AA]$ interactions. Furthermore, each layer of this assembly is connected to the next layer by means of $\mathrm{C}-\mathrm{H} \cdots \mathrm{F}$ $[\mathrm{C}(22)-\mathrm{H}(22) \cdots \mathrm{F}(1) 2.597 \AA], \mathrm{C}-\mathrm{H} \cdots \pi[\mathrm{C}(24)-\mathrm{H}(24) \cdots \mathrm{C}(15) 2.876 \AA, \mathrm{C}(20)-\mathrm{H}(20) \cdots \mathrm{C}(3) 2.828$ $\AA]$ ], $\mathrm{C}-\mathrm{H} \cdots \mathrm{O}[\mathrm{C}(17)-\mathrm{H}(17) \cdots \mathrm{O}(1) 2.601 \AA]$ and $\pi \cdots \pi[\mathrm{C}(9) \cdots \mathrm{N}(2) 3.232 \AA]$ interactions between anti-parallel stacked molecules of $\mathbf{2}$, providing an overall multi-layered structure (Figure 4c). 


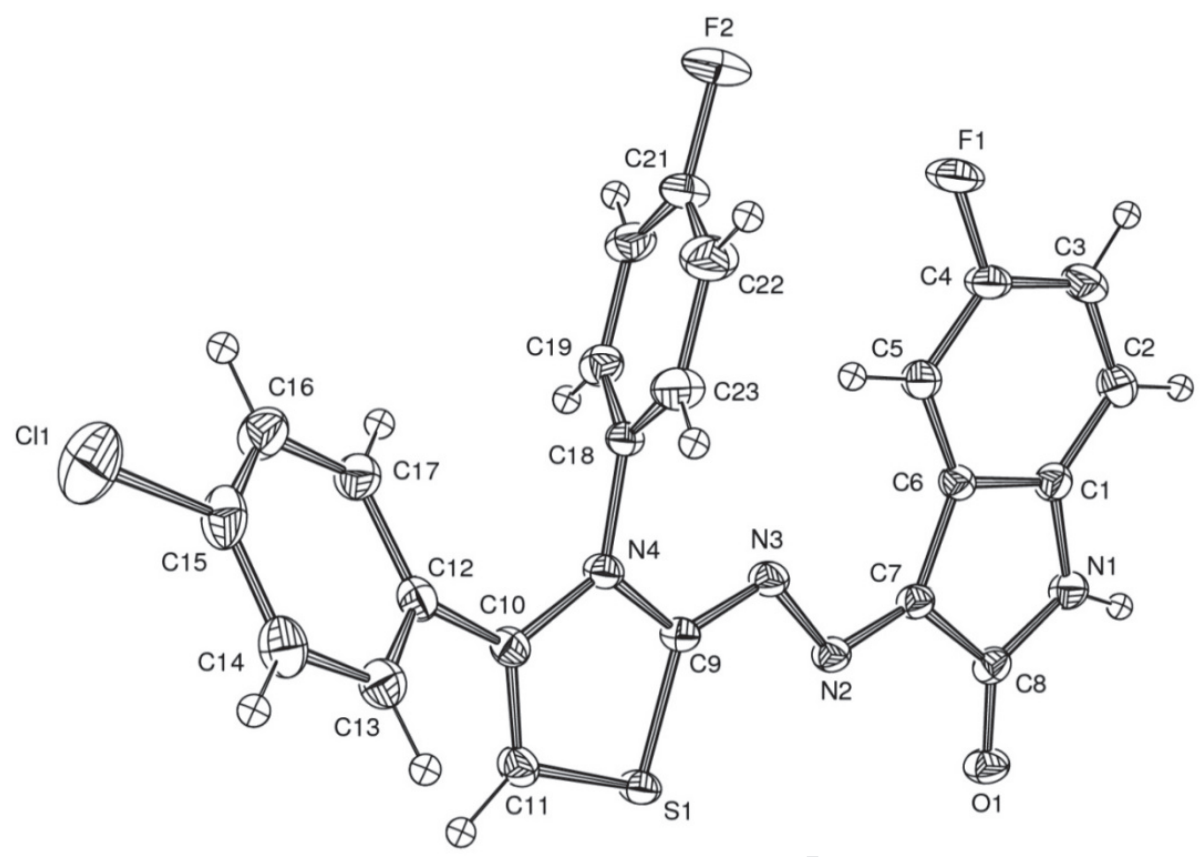

Figure 2. X-ray crystal structure of 2. Selected bond lengths $(\AA)$ : $\mathrm{Cl}(1)-\mathrm{C}(15)$ 1.373(16); $\mathrm{S}(1)$ $\mathrm{C}(9)$ 1.733(14); S(1)-C(11) 1.735(15); F(1)-C(4) 1.368(17); F(2)-C(21) 1.360(18); O(1)-C(8) 1.230(18); N(1)-C(8) 1.356(19); N(1)-C(1) 1.405(19); N(1)-H(1) 0.8800; N(2)-C(7) 1.298(19); $\mathrm{N}(2)-\mathrm{N}(3)$ 1.363(16); N(3)-C(9) 1.309(18); N(4)-C(9) 1.369(18); N(4)-C(10) 1.406(18); N(4)$\mathrm{C}(18)$ 1.443(17). Selected bond angles $\left({ }^{\circ}\right)$ : C(9)-S(1)-C(11) 90.10(7); C(8)-N(1)-C(1) 111.25(12); $\quad \mathrm{C}(7)-\mathrm{N}(2)-\mathrm{N}(3) \quad 111.95(12) ; \quad \mathrm{C}(9)-\mathrm{N}(3)-\mathrm{N}(2) \quad 111.84(12) ; \quad \mathrm{C}(9)-\mathrm{N}(4)-\mathrm{C}(10)$ 113.78(11); C(9)-N(4)-C(18) 118.44(11); C(10)-N(4)-C(18) 127.76(11).

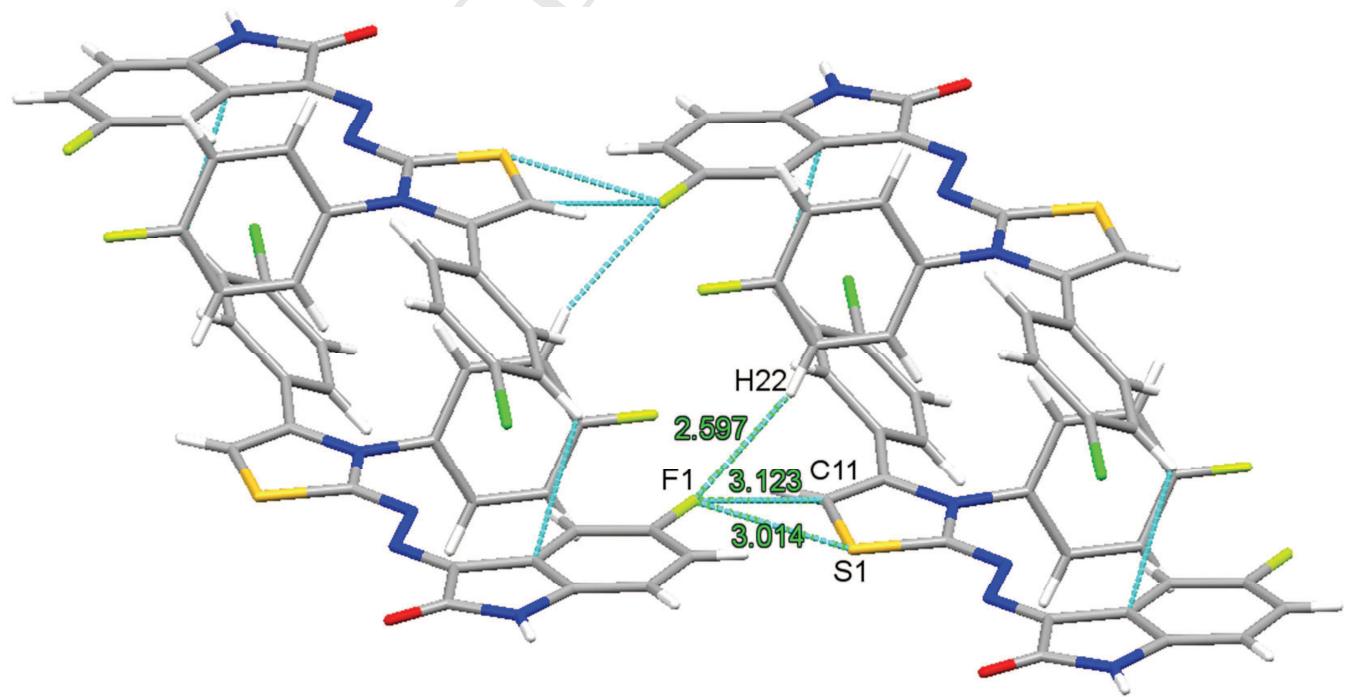

Figure 3. Crystal packing of 2 highlighting fluorine-mediated $\mathrm{C}-\mathrm{H} \cdots \mathrm{F}, \mathrm{F} \cdots \mathrm{S}$ and $\mathrm{F} \cdots \pi$ interactions 
Table 2. Non-covalent interactions stabilizing the methanol-encapsulated solid state selfassembly of compound 2

\begin{tabular}{lll}
\hline Interaction type & Atoms involved & Distance $(\AA)$ \\
\hline $\mathrm{C}-\mathrm{H} \cdots \mathrm{F}$ & $\mathrm{C}(22)-\mathrm{H}(22) \cdots \mathrm{F}(1)$ & 2.597 \\
$\mathrm{~F} \cdots \mathrm{S}$ & $\mathrm{C}(4)-\mathrm{F}(1) \cdots \mathrm{S}(1)$ & 3.014 \\
$\mathrm{~F} \cdots \pi$ & $\mathrm{C}(4)-\mathrm{F}(1) \cdots \mathrm{C}(11)$ & 3.123 \\
$\mathrm{~N}-\mathrm{H} \cdots \mathrm{O}$ & $\mathrm{N}(1)-\mathrm{H}(1) \cdots \mathrm{O}(2)$ & 1.981 \\
$\mathrm{O}-\mathrm{H} \cdots \mathrm{O}$ & $\mathrm{O}(2)-\mathrm{H}(2 \mathrm{~A}) \cdots \mathrm{O}(1)$ & 1.871 \\
$\mathrm{C}-\mathrm{H} \cdots \mathrm{O}$ & $\mathrm{C}(3)-\mathrm{H}(3) \cdots \mathrm{O}(2)$ & 2.521 \\
& $\mathrm{C}(2)-\mathrm{H}(2) \cdots \mathrm{O}(1)$ & 2.448 \\
& $\mathrm{C}(17)-\mathrm{H}(17) \cdots \mathrm{O}(1)$ & 2.601 \\
$\mathrm{C}-\mathrm{H} \cdots \pi$ & $\mathrm{C}(24)-\mathrm{H}(24) \cdots \mathrm{C}(15)$ & 2.876 \\
& $\mathrm{C}(20)-\mathrm{H}(20) \cdots \mathrm{C}(3)$ & 2.828 \\
$\mathrm{Cl} \cdots \pi$ & $\mathrm{Cl}(1) \cdots \mathrm{C}(20)$ & 3.406 \\
& $\mathrm{Cl}(1) \cdots \mathrm{C}(21)$ & 3.261 \\
$\pi \cdots \pi$ & $\mathrm{C}(9) \cdots \mathrm{N}(2)$ & 3.232 \\
\hline
\end{tabular}

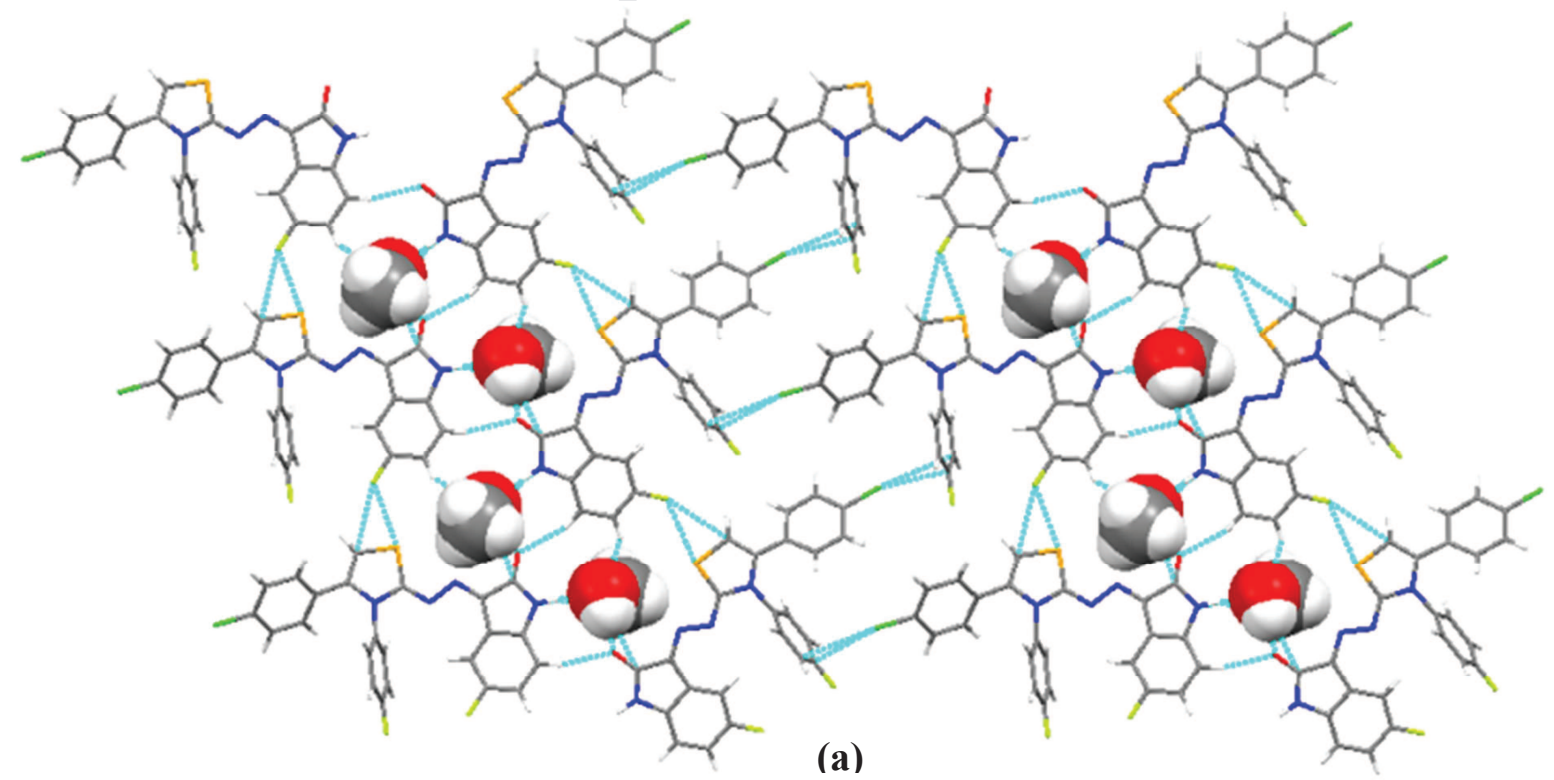



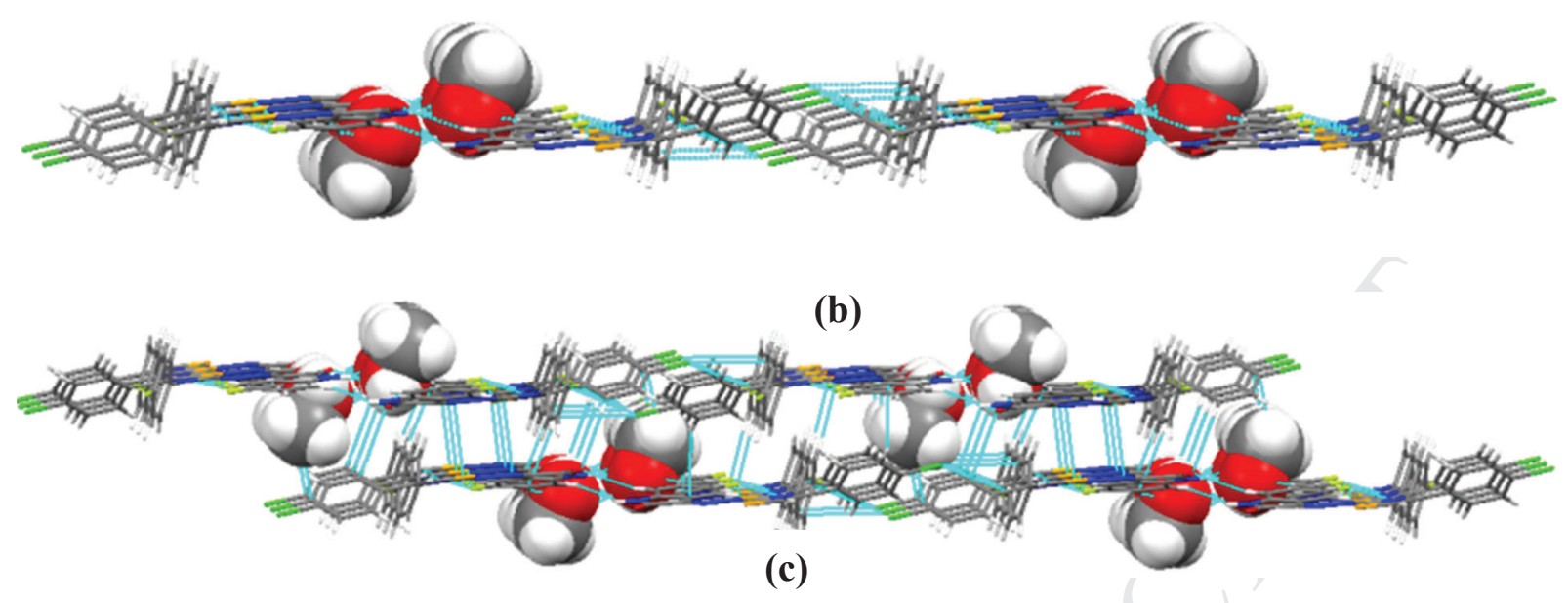

(c)

Figure 4.Crystal packing of compound 2: a) view of four neighbouring 1D-chains having methanol molecules encapsulated between two chains forming a bi-chain methanol sandwich along $a$-axis; b) view of a layer along $b$-axis; c) view of two consecutive layers along $b$-axis

To the best of our knowledge, fluorine-mediated $\mathrm{C}-\mathrm{H} \cdots \mathrm{F}, \mathrm{F} \cdots \mathrm{S}$ and $\mathrm{F} \cdots \pi$ interactions described here have not been reported so far in a family of isatin-based compounds. It is worth mentioning that $\mathrm{C}-\mathrm{H} \cdots \mathrm{O}$ interactions observed in $\mathbf{1}$ due to the presence of methoxy substituent are outweighed by the fluorine-mediated interactions found in the present case [32]. The introduction of fluoro substituent as a substitute to methoxy on the central aryl ring of $\mathbf{2}$ led to the appearance of fluorine-mediated interactions. The strategy to observe fluorine-mediated interactions used here could possibly be used in other rigid systems to explore and understand their positive effects on the biological properties of a specific drug molecule, in addition to their applications in crystal engineering field [47].

\section{Conclusions}

In summary, we have synthesized an interesting isatin-thiazoline hybrid molecule $\mathbf{2}$ and studied its solid state self-assembling behaviour by X-ray crystallography. A multi-layered methanol encapsulated network assembly, which is composed of various 1D-chains, has been observed. Fascinatingly, methanol molecules are sandwiched between two 1D-chains of this assembly. The 
notable supramolecular interactions involved in the stabilization of this assembly are $\mathrm{C}-\mathrm{H} \cdots \mathrm{F}$, $\mathrm{F} \cdots \mathrm{S}$ and $\mathrm{F} \cdots \pi$, which were not only absent in our previously reported isatin-thiazoline hybrid $\mathbf{1}$ but also, to the best of our knowledge, never reported earlier in the family of isatin-based compounds by other workers. As illustrated in the present example and also revealed from our previous study and the literature survey, fluorine-mediated interactions may occur even in the presence of other strong non-covalent interactions but it depends largely on the geometry of the molecules. Furthermore, they are not very weak interactions $(\mathrm{C}-\mathrm{H} \cdots \mathrm{F}=2.597 \AA)$ and may have significant ability to direct the molecular packing, which highlights their much larger role in the crystal packing than anticipated so far [47]. The general perception that organic fluorine hardly ever accepts hydrogen bond [14] has been found to gradually change during the past two decades and its structure directing role is now recognized [16]. However, to understand its role in biology and use as a reliable synthon in crystal engineering still needs more research.

\section{Acknowledgments}

We acknowledge partial funding of this research work and the award of indigenous $\mathrm{PhD}$ scholarship to MA by Higher Education Commission (HEC), Government of Pakistan.

\section{References}

[1] H.R. Ding, Y.X. Lu, W.H. Wu, H.L. Liu, Competing hydrogen bonding and halogen bonding interactions in crystal engineering: A case study of bi-functional donor molecules, Chemical Physics, 441 (2014) 30-37. 
[2] Q. Gou, G. Feng, L. Evangelisti, W. Caminati, Interaction between Freons and Amines: The $\mathrm{C}-\mathrm{H} \cdots \mathrm{N}$ Weak Hydrogen Bond in Quinuclidine-Trifluoromethane, Journal of Physical Chemistry A, 118 (2014) 737-740.

[3] E.M.D. Keegstra, V. vanderMieden, J.W. Zwikker, L.W. Jenneskens, A. Schouten, H. Kooijman, N. Veldman, A.L. Spek, Self-organization of 2,5-di-n-alkoxy-1,4benzoquinones in the solid state: Molecular recognition involving intermolecular dipoledipole, weak $\mathrm{C}-\mathrm{H} \cdots \mathrm{O}=\mathrm{C}$ hydrogen bond and vanderWaals interactions, Chemistry of Materials, 8 (1996) 1092-1105.

[4] A.C. Laungani, M. Keller, J.M. Slattery, I. Krossing, B. Breit, Cooperative Effect of a Classical and a Weak Hydrogen Bond for the Metal-Induced Construction of a SelfAssembled beta-Turn Mimic, Chemistry-a European Journal, 15 (2009) 10405-10422.

[5] G.R. Desiraju, Hydrogen bridges in crystal engineering: Interactions without borders, Accounts of Chemical Research, 35 (2002) 565-573.

[6] X.S. Wang, Q. Li, J.R. Wu, M.M. Zhang, Unclassical Hydrogen Bonds of C-H $\cdots \mathrm{N}$ and $\mathrm{C}-\mathrm{H} \cdots \mathrm{Cl}$ in the Crystal Structures of 2-((E)-1,3-diarylallylidene)malononitriles, Journal of Chemical Crystallography, 41 (2011) 59-63.

[7] M. Arshad, S. Saied, A. Ullah, PEG-lipid telechelics incorporating fatty acids from canola oil: synthesis, characterization and solution self-assembly, RSC Advances, 4 (2014) 26439-26446.

[8] A.C.C. de Melo, I.F. de Amorim, M.D. Cirqueira, F.T. Martins, Toward Novel SolidState Forms of the Anti-HIV Drug Efavirenz: From Low Screening Success to Cocrystals 
Engineering Strategies and Discovery of a New Polymorph, Crystal Growth \& Design, 13 (2013) 1558-1569.

[9] K. Biradha, R. Santra, Crystal engineering of topochemical solid state reactions, Chemical Society Reviews, 42 (2013) 950-967.

[10] S.K. Seth, D. Sarkar, A. Roy, T. Kar, Insight into supramolecular self-assembly directed by weak interactions in acetophenone derivatives: crystal structures and Hirshfeld surface analyses, CrystEngComm, 13 (2011) 6728-6741.

[11] L.S. Reddy, S.K. Chandran, S. George, N.J. Babu, A. Nangia, Crystal structures of Naryl-N'-4-nitrophenyl ureas: Molecular conformation and weak interactions direct the strong hydrogen bond synthon, Crystal Growth \& Design, 7 (2007) 2675-2690.

[12] J.A.K. Howard, V.J. Hoy, D. OHagan, G.T. Smith, How good is fluorine as a hydrogen bond acceptor?, Tetrahedron, 52 (1996) 12613-12622.

[13] V.R. Thalladi, H.C. Weiss, D. Blaser, R. Boese, A. Nangia, G.R. Desiraju, C-H $\cdots$ F interactions in the crystal structures of some fluorobenzenes, Journal of the American Chemical Society, 120 (1998) 8702-8710.

[14] J.D. Dunitz, R. Taylor, Organic fluorine hardly ever accepts hydrogen bonds, Chem-Eur J, 3 (1997) 89-98.

[15] A.R. Choudhury, T.N.G. Row, How realistic are interactions involving organic fluorine in crystal engineering? Insights from packing features in substituted isoquinolines, Cryst Growth Des, 4 (2004) 47-52. 
[16] D. Chopra, T.N.G. Row, Evaluation of the interchangeability of C-H and C-F groups: insights from crystal packing in a series of isomeric fluorinated benzanilides, Crystengcomm, 10 (2008) 54-67.

[17] K. Reichenbacher, H.I. Suss, J. Hulliger, Fluorine in crystal engineering - "the little atom that could", Chem Soc Rev, 34 (2005) 22-30.

[18] L. Pauling, Pauling, L. The Nature of the Chemical Bond; Cornell University Press: Ithaca, NY, 1960.

[19] E. D'Oria, J.J. Novoa, On the hydrogen bond nature of the C-H $\cdots \mathrm{F}$ interactions in molecular crystals. An exhaustive investigation combining a crystallographic database search and ab initio theoretical calculations, CrystEngComm, 10 (2008) 423-436.

[20] Y.F. Wang, S.R. Parkin, J. Gierschner, M.D. Watson, Highly fluorinated benzobisbenzothiophenes, Org Lett, 10 (2008) 3307-3310.

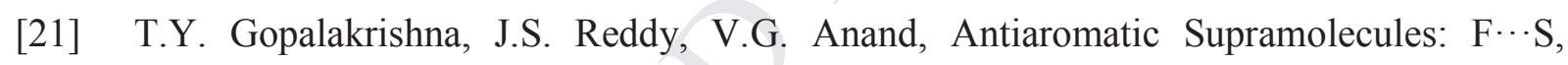
$\mathrm{F} \cdots \mathrm{Se}$, and $\mathrm{F} \cdots \pi$ Intermolecular Interactions in 32 pi Expanded Isophlorins, Angew Chem Int Edit, 52 (2013) 1763-1767.

[22] H.Y. Zhao, F.P. Gabbai, Nucleophilic Fluorination Reactions Starting from Aqueous Fluoride Ion Solutions, Org Lett, 13 (2011) 1444-1446.

[23] Y. Xia, S. Viel, Y. Wang, F. Ziarelli, E. Laurini, P. Posocco, M. Fermeglia, F.Q. Qu, S. Pricl, L. Peng, Rationalizing the F $\cdots \mathrm{S}$ interaction discovered within a tetrafluorophenylazido-containing bola-phospholipid, Chem Commun, 48 (2012) 42844286. 
[24] T.V. Rybalova, I.Y. Bagryanskaya, C-F...pi, F...H, and F...F intermolecular interactions and F-aggregation: Role in crystal engineering of fluoroorganic compounds, J Struct Chem+, 50 (2009) 741-753.

[25] D. OHagan, H.S. Rzepa, Some influences of fluorine in bioorganic chemistry, Chem Commun, (1997) 645-652.

[26] R. Duschinsky, E. Pleven, C. Heidelberger, The synthesis of 5-fluoropyrimidines, J. Am. Chem. Soc. , 79 (1957) 4559-4560.

[27] G.S. Singh, Z.Y. Desta, Isatins As Privileged Molecules in Design and Synthesis of Spiro-Fused Cyclic Frameworks, Chem Rev, 112 (2012) 6104-6155.

[28] J.F.M. da Silva, S.J. Garden, A.C. Pinto, The chemistry of isatins: a review from 1975 to 1999, J Brazil Chem Soc, 12 (2001) 273-324.

[29] M. Simard, D. Su, J.D. Wuest, Use of Hydrogen-Bonds to Control Molecular Aggregation - Self-Assembly of 3-Dimensional Networks with Large Chambers, J Am Chem Soc, 113 (1991) 4696-4698.

[30] D. Su, X. Wang, M. Simard, J.D. Wuest, Molecular tectonics, Supramol Chem, 6 (1995) $171-178$.

[31] J.H. Porada, J. Neudorfl, D. Blunk, Synthesis and Supramolecular Organization of 5-(4Alkylphenyl)isatin, Cryst Growth Des, 11 (2011) 3648-3652.

[32] M. Ahmad, H. Pervez, T. Ben Hadda, L. Toupet, M.M. Naseer, Synthesis and solid state self-assembly of an isatin-thiazoline hybrid driven by three self-complementary dimeric motifs, Tetrahedron Lett, 55 (2014) 5400-5403. 
[33] R. Jawaria, M. Hussain, Z. Shafiq, H.B. Ahmad, M.N. Tahir, H.A. Shad, M.M. Naseer, Robustness of thioamide dimer synthon, carbon bonding and thioamide-thioamide stacking in ferrocene-based thiosemicarbazones, CrystEngComm, 17 (2015) 2553-2561.

[34] Zia-ur-Rehman, M.M. Naseer, A. Shah, S. Ali, A. Meetsma, Steric and Electronic Influence on the Coordination Aptitude of 4-Formylpiperazine-1-Carbodithioate Towards Triorganotin(IV) Moieties, Heteroatom Chemistry, 26 (2015) 123-133.

[35] A. Abbas, H. Nazir, M.M. Naseer, M. Bolte, S. Hussain, N. Hafeez, A. Hasan, Synthesis, spectral characterization, self-assembly and biological studies of N-acyl-2-pyrazolines bearing long alkoxy side chains, Spectrochim Acta A, 120 (2014) 176-184.

[36] F. Anam, A. Abbas, K.M. Lo, Zia-ur-Rehman, S. Hameed, M.M. Naseer, Homologous 1,3,5-triarylpyrazolines: synthesis, $\mathrm{CH} \cdots \pi$ interactions guided self-assembly and effect of alkyloxy chain length on DNA binding properties, New Journal of Chemistry, 38 (2014) $5617-5625$.

[37] M.M. Naseer, S. Hameed, Layer-by-layer assembly of supramolecular hexagonal blocks driven by $\mathrm{CH}-\pi$ and $\pi-\pi$ interactions, Crystengcomm, 14 (2012) 4247-4250.

[38] A. Abbas, N. Flores-Holguin, M.M. Naseer, Structure-fluorescence relationship: interplay of non-covalent interactions in homologous 1,3,5-triaryl-2-pyrazolines. New $J$. Chem. (2015) DOI: 10.1039/C5NJ00179J.

[39] Ö. Dereli, S. Bahçeli, A. Abbas, M.M. Naseer, Quantum chemical investigations of a cocrystal of 1,3,5-tris(4-hydroxyphenyl)benzene and 2,4,6-trimethoxy-1,3,5-triazine. Monatsh Chem. (2015) DOI: 10.1007/s00706-015-1413-z. 
[40] R.B.K. Siram, D.P. Karothu, T.N.G. Row, S. Patil, Unique Type II Halogen $\cdots$ Halogen Interactions in Pentafluorophenyl-Appended 2,2 '-Bithiazoles, Cryst Growth Des, 13 (2013) 1045-1049.

[41] S.K. Nayak, M.K. Reddy, D. Chopra, T.N.G. Row, Evaluation of the role of disordered organic fluorine in crystal packing: insights from halogen substituted benzanilides, CrystEngComm, 14 (2012) 200-210.

[42] D. Chopra, T.N.G. Row, Role of organic fluorine in crystal engineering, CrystEngComm, 13 (2011) 2175-2186.

[43] H. Pervez, N. Saira, M.S. Iqbal, M. Yaqub, K.M. Khan, Synthesis and biological evaluation of some N (4)-aryl-substituted 5-fluoroisatin-3-thiosemicarbazones, Med Chem Res, 22 (2013) 5878-5889.

[44] A. Altomare, M.C. Burla, M. Camalli, G.L. Cascarano, C. Giacovazzo, A. Guagliardi, A.G.G. Moliterni, G. Polidori, R. Spagna, SIR97: a new tool for crystal structure determination and refinement, Journal of applied crystallography, 32 (1999) 115-119.

[45] G.M. Sheldrick, SHELX-97, Program for Crystal Structure refinement, University of Göttingen, Germany, 1997.

[46] A.L. Spek, PLATON Procedure, A multipurpose Crystallographic Tool, Utrecht University, Utrecht, The Netherlands, 1998.

[47] G. Althoff, J. Ruiz, V. Rodriguez, G. Lopez, J. Perez, C. Janiak, Can a single C-H $\cdots$ F-C hydrogen bond make a difference? Assessing the $\mathrm{H} \cdots \mathrm{F}$ bond strength from 2-D H-1-F-19 CP/MAS NMR, CrystEngComm, 8 (2006) 662-665. 


\section{Research Highlights:}

An isatin-thiazoline hybrid molecule having $-\mathrm{C}=\mathrm{N}-\mathrm{N}=\mathrm{C}$ - linkage has been synthesized.

Solid state self-assembly was studied by X-ray crystallographic technique.

A bi-chain sandwich like structure with methanol molecules encapsulated between every two chains is obtained.

Fluorine-mediated interactions are involved in the stabilization of this assembly. 


\section{checkCIF/PLATON report}

You have not supplied any structure factors. As a result the full set of tests cannot be run.

THIS REPORT IS FOR GUIDANCE ONLY. IF USED AS PART OF A REVIEW PROCEDURE FOR PUBLICATION, IT SHOULD NOT REPLACE THE EXPERTISE OF AN EXPERIENCED CRYSTALLOGRAPHIC REFEREE.

No syntax errors found. CIF dictionary Interpreting this report

\section{Datablock: shelx}

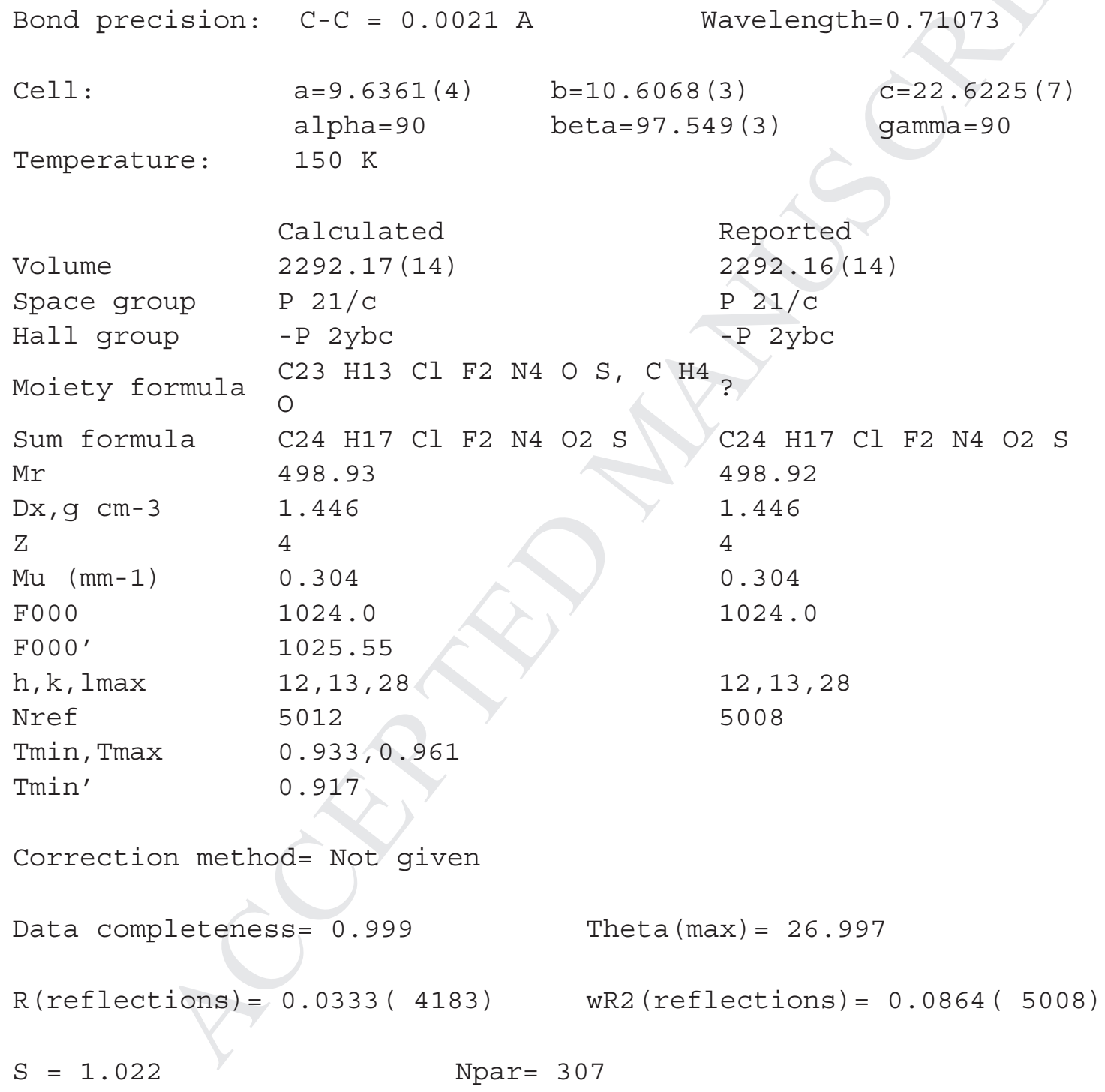


Alert level $\mathrm{C}$

PLAT790_ALERT_4_C Centre of Gravity not Within Unit Cell: Resd. \# 1 Note

C23 $\mathrm{H} 13$ Cl F2 N4 O S

Alert level G

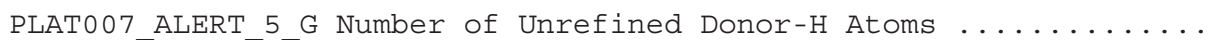
PLAT169_ALERT_4_G The CIF-Embedded.res File Contains AFIX 1 Recds PLAT790_ALERT_4_G Centre of Gravity not Within Unit Cell: Resd. \#

0 ALERT level $\mathbf{A}=$ Most likely a serious problem - resolve or explain

0 ALERT level B = A potentially serious problem, consider carefully

1 ALERT level $\mathbf{C}=$ Check. Ensure it is not caused by an omission or oversight

3 ALERT level $\mathbf{G}=$ General information/check it is not something unexpected

o ALERT type 1 CIF construction/syntax error, inconsistent or missing data

0 ALERT type 2 Indicator that the structure model may be wrong or deficient

0 ALERT type 3 Indicator that the structure quality may be low

3 ALERT type 4 Improvement, methodology, query or suggestion

1 ALERT type 5 Informative message, check

It is advisable to attempt to resolve as many as possible of the alerts in all categories. Often the minor alerts point to easily fixed oversights, errors and omissions in your CIF or refinement strategy, so attention to these fine details can be worthwhile. In order to resolve some of the more serious problems it may be necessary to carry out additional measurements or structure refinements. However, the purpose of your study may justify the reported deviations and the more serious of these should normally be commented upon in the discussion or experimental section of a paper or in the "special_details" fields of the CIF. checkCIF was carefully designed to identify outliers and unusual parameters, but every test has its limitations and alerts that are not important in a particular case may appear. Conversely, the absence of alerts does not guarantee there are no aspects of the results needing attention. It is up to the individual to critically assess their own results and, if necessary, seek expert advice.

\section{Publication of your CIF in IUCr journals}

A basic structural check has been run on your CIF. These basic checks will be run on all CIFs submitted for publication in IUCr journals (Acta Crystallographica, Journal of Applied Crystallography, Journal of Synchrotron Radiation); however, if you intend to submit to Acta Crystallographica Section $C$ or $E$, you should make sure that full publication checks are run on the final version of your CIF prior to submission.

\section{Publication of your CIF in other journals}

Please refer to the Notes for Authors of the relevant journal for any special instructions relating to CIF submission.

PLATON version of 21/04/2015; check.def file version of 09/03/2015 
Datablock shelx - ellipsoid plot

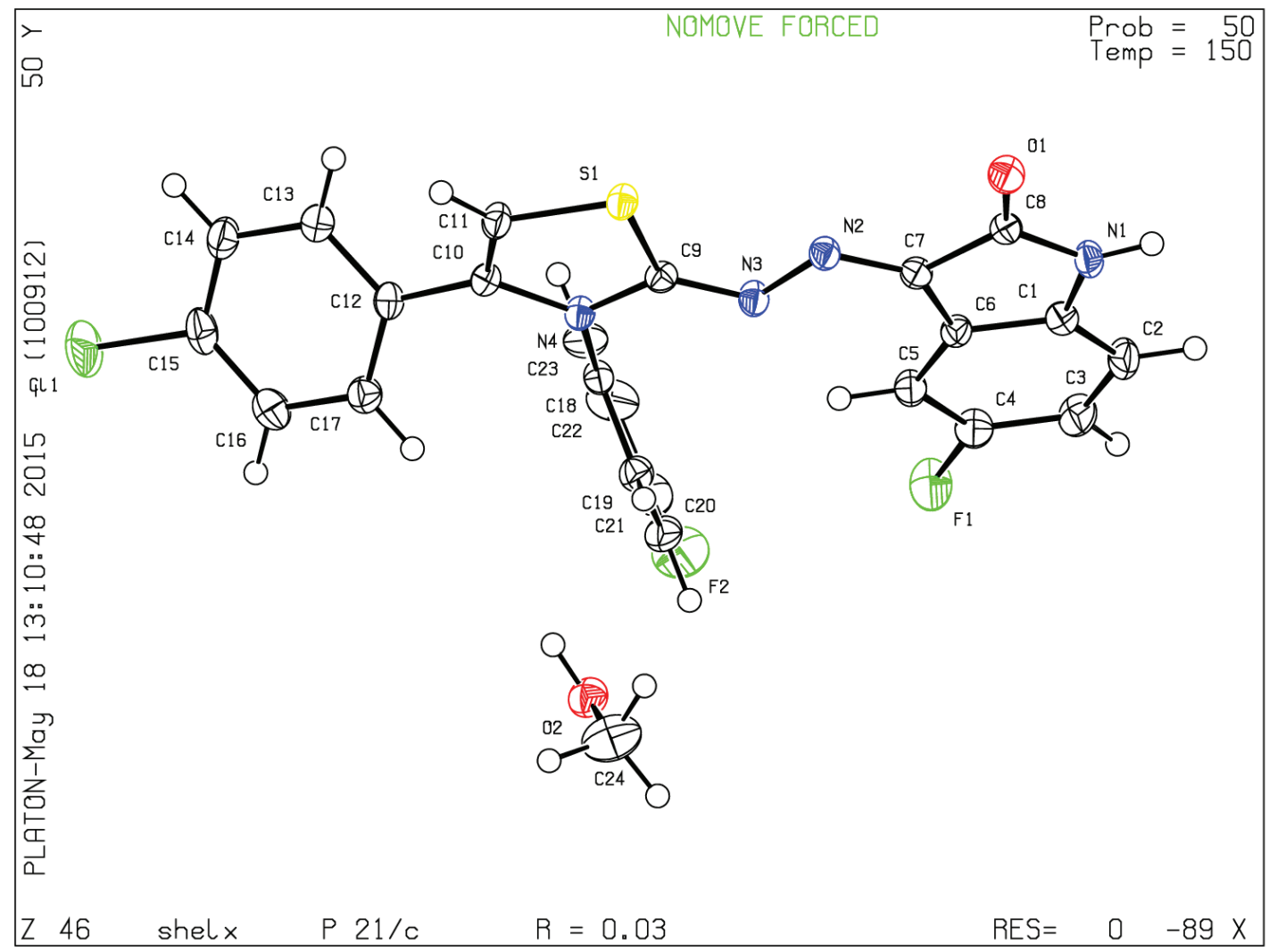

